\title{
Risk factors for drug allergies in Chinese children
}

\author{
Jaime S Rosa Duque, ${ }^{1}$ Daniel KL Cheuk, ${ }^{1}$ Patrick CY Chong, ${ }^{1}$ Patrick Ip, ${ }^{1}$ Wilfred HS Wong, ${ }^{1}$ Pamela PW Lee, ${ }^{1}$ \\ Ian CK Wong, ${ }^{2,3}$ Godfrey CF Chan, ${ }^{1}$ Yu-Lung Lau, ${ }^{1}$ Marco HK Ho ${ }^{1}$
}

\begin{abstract}
Background: Drug allergy, or drug hypersensitivity, is a potentially fatal disorder, and patients labeled with drug allergies have restricted access to first-line treatments. Full knowledge of the characteristics associated with drug allergies and severe reactions during allergy evaluation is beneficial for appropriate risk stratification.
\end{abstract}

Objective: We sought to determine whether certain clinical characteristics are associated with drug allergies in Chinese children.

Methods: Charts were reviewed for ethnic Chinese patients less than 18 years old referred to our tertiary allergy center for suspected drug allergies and completed skin and drug provocative testing between 2005 to 2017. Univariate and multivariate analyses were performed on the age of onset of drug allergies, gender, and other atopy versus drug allergies.

Results: Out of 75 children, 18 (24\%) had IgE-mediated drug allergies, while 8 (10.7\%) had delayed drug hypersensitivities, with a cumulative 26 subjects $(34.7 \%)$ with any drug hypersensitivity. There were positive independent associations between drug hypersensitivities onset age vs IgE-mediated drug allergies (odds ratio $(\mathrm{OR})=14.9$, 95\% confidence intervals $(\mathrm{CIs})=1.5-148.3, P=0.017)$ and between male gender and IgE-mediated drug allergies $(\mathrm{OR}=4.4$, CIs $=$ 1.2-16.4, $P=0.019)$. Age 13 years was the best cut-off for IgE-mediated drug allergies according to the receiver operating characteristic curve $(P=0.026)$. Older age group $(\mathrm{OR}=24.0, \mathrm{CIs}=1.4-417.8, P=0.024)$ and atopic dermatitis $(\mathrm{OR}=8.2$, CIs $=1.4-49.8, P=0.015)$ were correlated with delayed drug hypersensitivities.

Conclusions: While several previous studies suggested a higher prevalence of IgE-mediated drug allergies in younger adult females, older boys were more likely to have drug allergies for Chinese children.

Keywords: allergy, anaphylaxis, challenge, drug, epidemiology, IgE, paediatric, pharmacogenomics, pharmacology, provocative, skin testing

\section{From:}

${ }^{1}$ Department of Paediatrics and Adolescent Medicine, Queen Mary Hospital, Li Ka Shing Faculty of Medicine, The University of Hong Kong, Hong Kong

${ }^{2}$ Department of Pharmacology and Pharmacy, Li Ka Shing Faculty of Medicine, The University of Hong Kong, Hong Kong

${ }^{3}$ Research Department of Practice and Policy,

UCL School of Pharmacy, London, United Kingdom

Corresponding author:

Jaime S Rosa Duque

Department of Paediatrics and Adolescent Medicine

Room 115, New Clinical Bldg

Queen Mary Hospital, 102 Pokfulam Road

E-mail: jsrduque@hku.hk

\section{Abbreviations}

AUC area under the curve

CI 95\% confidence interval

COX inhibitor cyclooxygenase inhibitor

EHR electronic health record

$\begin{array}{ll}\text { Abbreviations } & \text { (Continued) } \\ \text { DIHS } & \begin{array}{l}\text { drug-induced hypersensitivity syndrome } \\ \text { drug reaction with eosinophilia and systemic symp- } \\ \text { DRESS }\end{array} \\ \text { toms } \\ \text { hIV } & \text { Hong Kong immunodeficiency virus } \\ \text { HK } & \text { human leukocyte antigen } \\ \text { HLA } & \text { odds ratio } \\ \text { OR } & \text { Queen Mary Hospital } \\ \text { QMH } & \text { receiver operating characteristic } \\ \text { ROC } & \end{array}$

\section{Introduction}

Drug allergies, or drug hypersensitivities, are a major public health concern that have a substantial impact on morbidity and inflict a huge economic burden on society. ${ }^{1}$ Epidemiological studies from the United States, Europe, Australia, and South America have ranked drug allergies as the most likely etiology for anaphylactic deaths. ${ }^{2-5}$ Unfortunately, 
the prevalence of fatal anaphylactic events has been on the upward trend in many parts of the world. . $^{1,2,4,6,7}$ Patients who suffer from drug-induced anaphylaxis are also at a greater risk of biphasic reactions than those with food or venom allergies, and they are more likely to experience more severe complications requiring hospitalization. ${ }^{2,8}$ Anaphylactic reactions are more likely secondary to foods in the paediatric population, but drug allergy remains as a common culprit. ${ }^{9,10}$

Many patients present to medical practitioners with extensive lists of suspected drug allergies, such as IgE-mediated drug allergies and delayed drug hypersensitivities including maculopapular and fixed drug eruptions, drug-induced hypersensitivity syndrome (DIHS)/drug reaction with eosinophilia and systemic symptoms (DRESS), Steven-Johnson syndrome/ toxic epidermal necrolysis, acute generalised exanthematous pustulosis, and allergic contact dermatitis. ${ }^{11,12}$ Often, due to convenience and safety, alternative therapies are chosen for these patients without a comprehensive allergy evaluation to determine whether they are truly allergic and whether induction of temporary tolerance, or desensitization, to first-line medications should be undertaken. ${ }^{12,13}$ Indeed, many patients with documented drug allergy spontaneously lose their sensitivity over time. ${ }^{13}$ Additionally, some patients were never allergic to begin with, and their symptoms might have been due to infectious exanthem or other underlying diseases, environmental factors, pharmacological side effects not due to immunologic causes, or non-reproducible, idiopathic events. ${ }^{12,13}$ Allergy protocols implemented to confirm or induce tolerance to first-line antimicrobials can minimize treatment failures and bacterial resistance. ${ }^{12,14}$ As such, it is now recommended that for those who require beta-lactam antimicrobial treatment but had reported a history of penicillin allergy, skin (ST) and drug provocation testing (DPT) should be undertaken if possible before alternative medications are prescribed..$^{12}$ This approach has been shown to be cost-saving for individual patients and the entire healthcare system. ${ }^{12,14}$

However, allergy testing involves risks, including lifethreatening reactions or death. ${ }^{12,13,15}$ Pretest risk stratification is important for identifying candidates who are likely to truly have drug allergies so that the appropriate setting, personnel, and equipment can be prearranged for these higher risk cases. ${ }^{12,13,15}$ Currently, risk factors predictive of patients with drug allergies have not been clearly identified. In some studies on adults, young women with multiple antibiotic allergies were more likely to have IgE-mediated drug allergies. ${ }^{16,17}$ Interestingly, a cohort of Korean children who had allergies to medications tended to be older. ${ }^{18}$ However, another study examining beta-lactam antibiotic drug allergies in a Middle Eastern paediatric population failed to establish these links but found that personal and family histories of drug allergies were most important, whereas human immunodeficiency virus (HIV) status was a strong predictor in Thai children. ${ }^{19,20}$ These diverse findings could be due to the fact that different ethnic and genetic backgrounds, environmental surroundings, disease prevalence in different regions, cultural and dietary habits, medication availability, and prescription practices all play a role in modulating the immune system and susceptibility of a patient towards a true and persistent drug allergy. ${ }^{21}$
Our institution is a major public referral center in Hong Kong (HK) that provides tertiary allergy care to children with suspected or confirmed drug allergies. ${ }^{15}$ The primary aim of this 13-year retrospective study was to identify whether age, gender, and other atopy such as atopic dermatitis, food allergies, asthma, and allergic rhinitis were associated risk factors for IgE-mediated drug allergies and delayed drug hypersensitivities in paediatric Chinese patients. The secondary aims included characterizing the prevalence of drug allergies for patients in this locality and the types of medications that were involved.

\section{Methods \\ Study Population}

All aspects of this study of human subjects were approved by the HK West Cluster Hospital Authority Research Ethics Committee Institutional Review Board without the need for patient and legal guardian consent due to its retrospective nature. Children suspected of having drug allergies in our locality were referred to our allergy clinic or seen by our inpatient allergy service during their hospital stay at Queen Mary Hospital (QMH) for initial evaluation. Most of these patients were of Chinese descent and residents of Hong Kong. A minority consisted of children from Guangdong Province referred to QMH paediatric subspecialists for their complex cardiac, oncologic, or rheumatologic disorders. Those with a history of non-life-threatening allergic reactions after medication exposures received ST and/or DPT at our Day Center, whereas in-patient DPT was performed for those who previously experienced severe reactions. Since January 2005, their data were recorded in a logbook and our Clinical Management System electronic health record (EHR) system accessible by all public hospitals in the city. ${ }^{22}$ Information from a comprehensive chart review between 1 January 2005 to 31 December 2017 which included previous referral information and symptoms, testing results, final diagnoses, onset of drug allergy, age, gender, and other atopic conditions was retrieved and stored in an encrypted file.

Children $<18$ years old who received skin prick, intradermal, atopy patch, and/or DPT to all suspected culprit drugs were included, and patients with allergies to multiple medications with known cross-reactivity were coded in the database as a single subject and drug allergy. Our testing modality followed international guidelines. ${ }^{13,23,24}$ ST was performed for beta-lactams which had well-established non-irritating concentration (NIC) and patients were deemed allergic if results were positive. ${ }^{13,25}$ All patients who were thought be allergic to medications without known NIC or had negative ST underwent DPT. A subject who demonstrated positive allergy testing to $\geq 1$ other non-cross-reactive medication were still considered as a single subject but with multiple drug allergies. To further understand the influence of age groups in drug allergies, 13 years old was used as the cutoff based on a common practice to differentiate paediatric patients as adolescents versus young children. Patients who did not fully complete the aforementioned testing, had ambiguous diagnosis at the time of data extraction, patients $\geq 18$ years old, and non-ethnic Chinese were excluded. 


\section{Statistical Analysis}

Power analyses were performed using $G^{\star}$ Power (Heinrich-Heine-Universität Düsseldorf, Düsseldorf, Germany) with $80 \%$ power at $5 \%$ level of significance in two tails. The effect size estimation was based on the findings from this study to demonstrate the sample sizes needed for different factors to reach the significant level associated with the outcomes of interest. Cohen's $d$ was estimated by using mean differences and standard deviations of continuous outcomes between groups. The Cohen's $d$ values were then used to calculate the sample sizes needed to detect a significant difference for each continuous outcome between two groups. Odds ratios were used instead of Cohen's $d$ if the outcome was a categorical measurement.

Demographic information and results are presented as group medians and $95^{\text {th }}$ interpercentile ranges or confidence intervals. Stepwise multivariate logistic regression with the forward selection method was used to detect independent associations with the outcomes of interest, and $P<0.05$ was considered significant. Statistical comparisons were completed using SPSS (IBM, Armonk, NY, USA) and JMP (SAS Institute, Cary, NC, USA).

\section{Results}

\section{Patient characteristics}

This study had adequate power to detect associations between age of onset vs IgE-mediated drug allergies, delayed drug hypersensitivities, and any drug hypersensitivity (Table 1). Of the 75 patients, there was a predominance of children $<13$ years old $(89.3 \%)$, with a median age of 3.0 years old (Table 2). Forty-one (54.7\%) of all subjects were males. Eighteen were confirmed to have IgE-mediated drug allergies, 8 had delayed drug hypersensitivities, equating to 26 (34.7\%)
Table 1. Power analyses for drug allergy outcomes of interest.

\begin{tabular}{|lcc|}
\hline IgE-mediated Drug Allergies & Effect Sizes & $\begin{array}{c}\text { Sample Size } \\
\text { Needed }\end{array}$ \\
\hline Age of onset (continuous) & $d=0.692$ & 68 \\
\hline Age of onset (adolescent) & OR $=25$ & 66 \\
\hline Gender & OR $=3.5$ & 92 \\
\hline Total numbers of atopic disease & $d=0.295$ & 362 \\
\hline Any atopy & OR $=1.92$ & 312 \\
\hline Delayed Drug Hypersensitivities & Effect Sizes & Sample Size \\
\hline Age onset (continuous) & $d=0.34$ & 272 \\
\hline Age of onset (adolescent) & OR $=14.2$ & 32 \\
\hline Gender & OR $=0.56$ & 785 \\
\hline Total numbers of atopic disease & $d=0.1$ & 3020 \\
\hline Any atopy & OR $=3.36$ & 218 \\
\hline Any Drug Hypersensitivity & Effect Sizes & Sample Size \\
\hline Age onset (continuous) & $d=0.59$ & 92 \\
\hline Age of onset (adolescent) & OR $=21.4$ & 73 \\
\hline Gender & OR $=1.94$ & 296 \\
\hline Total numbers of atopic disease & $d=0.39$ & 210 \\
\hline Any atopy & OR $=2.2$ & 218 \\
\hline No & & 92 \\
\hline
\end{tabular}

All power analyses performed with $1-\beta=0.80$ and two-tailed level of significance at 0.05 .

$d$, Cohen's $d$; OR, odds ratio; adolescent, grouped by $<13$ vs $\geq 13$ years old.

Table 2. Clinical characteristics of all 75 subjects in the study.

\begin{tabular}{|c|c|c|c|c|c|}
\hline & $\begin{array}{l}\text { All Subjects } \\
\qquad(n=75)\end{array}$ & $\begin{array}{l}\text { IgE-mediated } \\
\text { Drug Allergies } \\
\quad(n=18)\end{array}$ & $\begin{array}{c}\text { Delayed Drug } \\
\text { Hypersensitivities } \\
\qquad(n=8)\end{array}$ & $\begin{array}{c}\text { Any Drug } \\
\text { Hypersensitivity } \\
(n=26)\end{array}$ & $\begin{array}{l}\text { No Drug } \\
\text { Allergy } \\
(n=49)\end{array}$ \\
\hline Age of drug hypersensitivities onset (yrs) & $3.0(0.2-16.2)$ & $5.5(0.2-17.5)$ & $4.5(0.8-16.0)$ & $5.5(0.2-17.5)$ & $3.0(0.1-12.5)$ \\
\hline Age group at drug hypersensivities onset ( $0-5$ years old) & $47(62.7 \%)$ & $9(50.0 \%)$ & $4(50 \%)$ & $13(50 \%)$ & $34(69.4 \%)$ \\
\hline Age group at drug hypersensivities onset (6-12 years old) & $20(26.7 \%)$ & $4(22.2 \%)$ & $2(25.0 \%)$ & $6(23.3 \%)$ & $14(28.6 \%)$ \\
\hline Age group at drug hypersensivities onset ( $\geq 13$ years old) & $8(10.7 \%)$ & $5(27.8 \%)$ & $2(25.0 \%)$ & $7(26.9 \%)$ & $1(2.0 \%)$ \\
\hline Age at testing (yrs) & $6.2(0.6-17.8)$ & $11.2(0.8-17.8)$ & $5.9(1.4-18.0)$ & $8.4(0.8-18.0)$ & $6.1(0.5-16.7)$ \\
\hline Age group on testing date ( $0-5$ years old $)$ & $35(46.7 \%)$ & $7(38.9 \%)$ & $4(50 \%)$ & $11(42.3 \%)$ & $24(50.0 \%)$ \\
\hline Age group on testing date (6-12 years old) & $24(32.0 \%)$ & $2(11.1 \%)$ & $2(25.0 \%)$ & $4(15.4 \%)$ & $20(40.8 \%)$ \\
\hline Age group on testing date ( $\geq 13$ years old) & $16(21.3 \%)$ & $9(52.3 \%)$ & $2(25.0 \%)$ & $11(42.3 \%)$ & $5(10.2 \%)$ \\
\hline Male gender & $41(54.7 \%)$ & $14(77.8 \%)$ & $3(37.5 \%)$ & $17(65.4 \%)$ & $24(50.0 \%)$ \\
\hline History of atopic dermatitis & $18(24.0 \%)$ & $3(16.7 \%)$ & $5(62.5 \%)$ & $8(30.8 \%)$ & $10(20.4 \%)$ \\
\hline History of suspected IgE-mediated food allergies & $12(16.0 \%)$ & $3(16.7 \%)$ & $3(37.5 \%)$ & $6(23.3 \%)$ & $6(12.2 \%)$ \\
\hline History of allergic rhinitis & $24(32.0 \%)$ & $9(50.0 \%)$ & $2(25.0 \%)$ & $11(42.3 \%)$ & $13(26.5 \%)$ \\
\hline History of asthma & $19(25.3 \%)$ & $5(27.8 \%)$ & $3(25.0 \%)$ & $7(26.9 \%)$ & $12(24.5 \%)$ \\
\hline
\end{tabular}


Table 2. (Continued)

\begin{tabular}{|c|c|c|c|c|c|}
\hline & $\begin{array}{l}\text { All Subjects } \\
\quad(n=75)\end{array}$ & $\begin{array}{l}\text { IgE-mediated } \\
\text { Drug Allergies } \\
\quad(n=18)\end{array}$ & $\begin{array}{l}\text { Delayed Drug } \\
\text { Hypersensitivities } \\
\qquad(n=8)\end{array}$ & $\begin{array}{c}\text { Any Drug } \\
\text { Hypersensitivity } \\
(n=26)\end{array}$ & $\begin{array}{l}\text { No Drug } \\
\text { Allergy } \\
(n=49)\end{array}$ \\
\hline History of any of the above allergic diseases & $43(57.3 \%)$ & $12(66.7 \%)$ & $7(75.0 \%)$ & $18(69.2 \%)$ & $25(51.0 \%)$ \\
\hline Suspected multiple drug hypersensitivities & $21(28.0 \%)$ & $7(38.9 \%)$ & $3(37.5 \%)$ & $10(38.5 \%)$ & $11(22.4 \%)$ \\
\hline Confirmed multiple drug hypersensitivities & $10(13.0 \%)$ & $9(50.0 \%)$ & $1(12.5 \%)$ & $10(38.5 \%)$ & $0(0 \%)$ \\
\hline Reported immediate onset ( $<2 \mathrm{hrs}$ ) of symptoms & $26(34.7 \%)$ & $14(77.8 \%)$ & $0(0 \%)$ & $14(53.8 \%)$ & $12(24.5 \%)$ \\
\hline
\end{tabular}

Data are medians (and 95\% interpercentile ranges) or counts (and percentages).

with any drug hypersensitivity. Drug allergy was ruled out for the remaining 49 patients (65.3\%). Atopic conditions were similar amongst the different diagnostic groups, with a slightly higher prevalence in patients with drug allergies. Half of the patients with IgE-mediated drug allergies had ST or DPT positive to other medications (confirmed multiple drug hypersensitivities). Eleven out of 21 (52.4\%) of those who had suspected multiple drug allergies were found to have no drug allergy at all after several sessions of ST and DPT, whereas 7 (33.3\%) had a single drug allergy. Interestingly, no individual with delayed drug hypersensitivities reported immediate onset $(<2 \mathrm{hrs})$ of symptoms during their initial allergic presentation, while $4 / 18(22.2 \%)$ with IgE-mediated drug allergies reported delayed onset ( $\geq 2 \mathrm{hrs}$ ) of symptoms.

\section{Univariate logistic regression between patient characteristics and drug allergies}

Older age was significantly associated with higher odds of IgE-mediated drug allergies and any drug hypersensitivity $(P<0.05)$ (Table 3$)$. This correlation was more pronounced when patients were dichotomized into two groups: young children $(<13$ years old) versus adolescents $(\geq 13$ years old $)$ $(P<0.01)$. Males were more likely to have IgE-mediated drug allergies than females $(P=0.030)$. Patients $\geq 13$ years old or with a history of atopic dermatitis had significantly higher odds of delayed drug hypersensitivities $(P<0.05)$.

Table 3. Univariate logistic regression with odds ratios between patient characteristics and drug hypersensitivities.

\begin{tabular}{|c|c|c|c|c|c|c|}
\hline & $\begin{array}{l}\text { Odds Ratios } \\
\text { and 95\% CIs for } \\
\text { IgE-mediated } \\
\text { Drug Allergies }\end{array}$ & $P$ value & $\begin{array}{l}\text { Odds Ratios } \\
\text { and } 95 \% \text { CIs for } \\
\text { Delayed Drug } \\
\text { Hypersensitivities }\end{array}$ & $P$ value & $\begin{array}{l}\text { Odds Ratios and } \\
\text { 95\% CIs for } \\
\text { Any Drug } \\
\text { Hypersensitivity }\end{array}$ & $P$ value \\
\hline Age of drug hypersensitivities onset (yrs) & $11.0(1.2-95.6)$ & $0.026^{*}$ & $7.0(0.5-105.2)$ & 0.163 & $8.8(1.3-57.9)$ & $0.020^{*}$ \\
\hline Age group at drug hypersensitivities onset (adolescent) & $18.5(2.0-172.2)$ & $0.002^{*}$ & $16.0(1.3-204.1)$ & $0.029^{*}$ & $17.7(2.0-153.6)$ & $0.001^{*}$ \\
\hline Age at testing (yrs) & $13.4(1.8-99.1)$ & $0.008^{*}$ & $2.5(0.2-41.4)$ & 0.522 & $7.1(1.3-38.7)$ & $0.020^{*}$ \\
\hline Age group on testing date (adolescent) & $8.8(2.4-32.5)$ & $<0.001^{*}$ & $2.9(0.5-18.6)$ & 0.279 & $6.5(1.9-21.6)$ & $0.002^{*}$ \\
\hline Male gender & $3.6(1.1-12.7)$ & $0.030^{*}$ & $0.6(0.1-2.9)$ & 0.544 & $2.0(0.7-5.3)$ & 0.172 \\
\hline History of atopic dermatitis & $0.78(0.2-3.2)$ & 0.728 & $6.5(1.3-31.9)$ & $0.019^{*}$ & $1.7(0.6-5.1)$ & 0.323 \\
\hline History of suspected IgE-mediated food allergies & $0.70(0.2-3.1)$ & 0.644 & $0.23(0-1.2)$ & 0.100 & $0.46(0.1-1.6)$ & 0.233 \\
\hline History of allergic rhinitis & $0.36(0.1-1.1)$ & 0.075 & $1.1(0.2-6.1)$ & 0.927 & $0.49(0.2-1.3)$ & 0.167 \\
\hline History of asthma & $0.84(0.2-2.9)$ & 0.785 & $0.97(0.2-5.3)$ & 0.975 & $0.88(0.3-2.6)$ & 0.818 \\
\hline History of any of the above allergic diseases & $0.52(0.2-1.6)$ & 0.249 & $0.35(0.1-1.9)$ & 0.196 & $0.46(0.2-1.3)$ & 0.125 \\
\hline
\end{tabular}

Data are odds ratios (and 95\% confidence intervals). ${ }^{\star}, P<0.05$.

Adolescent, grouped by $<13$ vs $\geq 13$ years old. 
A

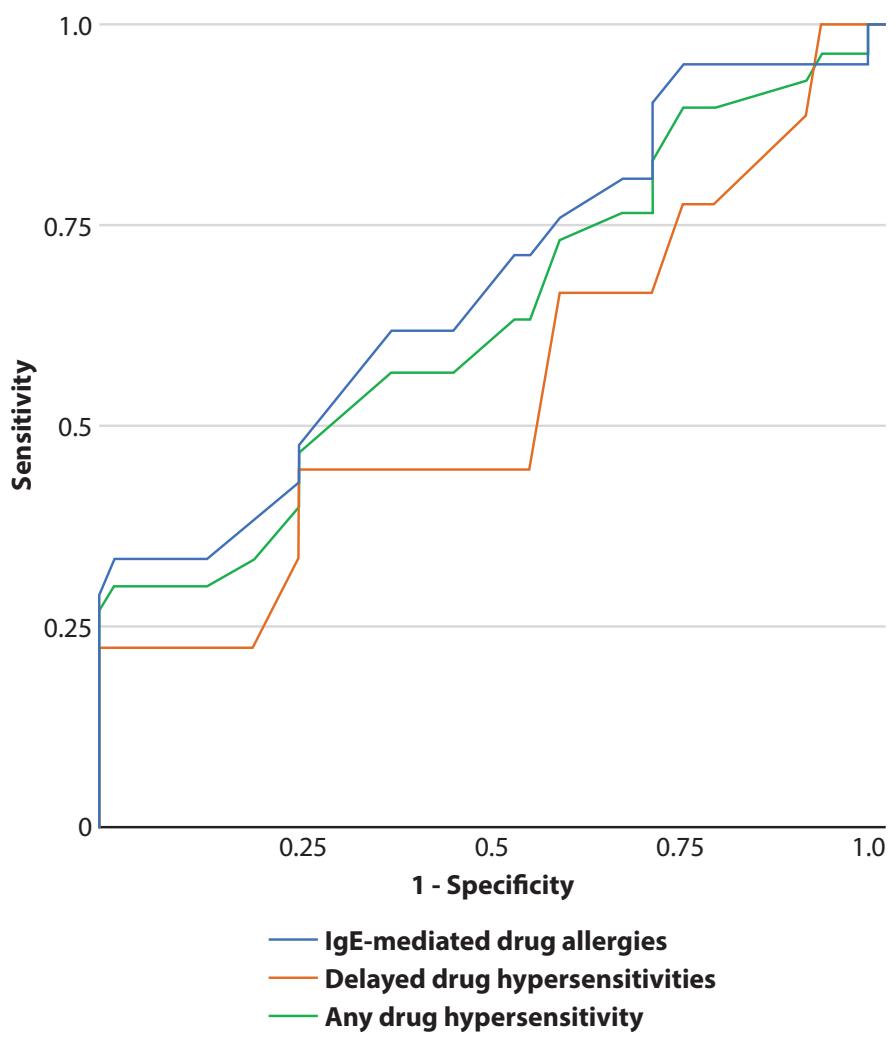

B

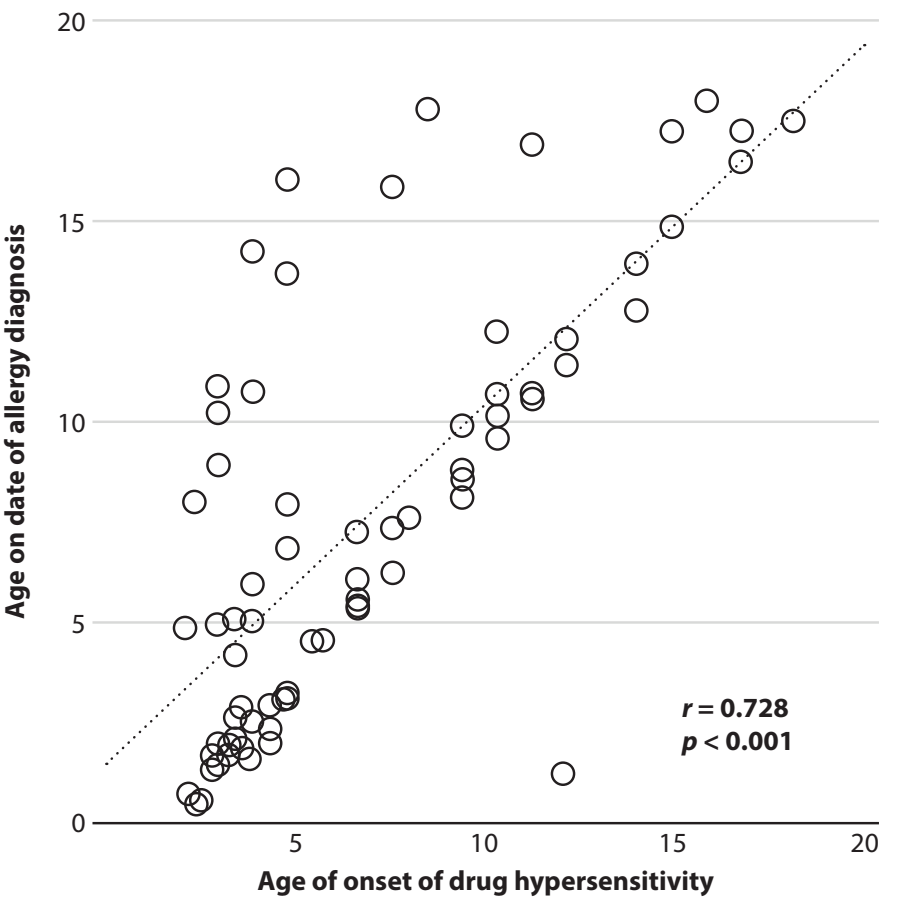

Figure 1. (Figure 1A) Receiver operating characteristics (ROCs) analyses indicated that the onset age of drug allergies had significant associations with IgE-mediated drug allergies (orange; area under the curve $(\mathrm{AUC})=0.648, P<0.01$ ) and any drug hypersensitivity (blue; AUC $=0.631, P<0.05$ ), with the highest levels of sensitivity and specificity at 13 years old. A cutoff of $\mathbf{1 5}$ years of onset age was suggested to have the highest sensitivity and specificity although there was no significant association between the age of onset and delayed drug hypersensitivities (turquoise; AUC $=0.594, P=0.16$ ). (Figure 1B) There was a high level of correlation $(r=0.728, P<0.001)$ between the age of onset of drug hypersensitivities and the age on the date of allergy diagnosis (by skin or drug provocative testing).

Use of age $\geq 13$ years as cutoff to compare age-group differences

To further investigate the possibility of a better age cutoff than 13 years old, we performed the receiver operating characteristic (ROC) analyses. Interestingly, the ROCs confirmed that 13 years was the cutoff age with the highest sensitivities and specificities for IgE-mediated drug allergies (area under the curve $(\mathrm{AUC})=0.648, P<0.01$; sensitivity $=27.8 \%$, specificity $=98.0 \%)$ and any drug hypersensitivity $(\mathrm{AUC}=0.631$, $P<0.05$; sensitivity $=26.9 \%$, specificity $=98.0 \%)$, respectively (Figure 1A). In contrast, for delayed drug hypersensitivities, the optimal age was 15 years, although this finding was not statistically significant $(\mathrm{AUC}=0.594, P=0.16$; sensitivity $=$ $25.0 \%$, specificity $=100 \%)$.

A potential confounding issue with using the age of onset is the possibility of recall bias, as patients and parents might not remember precisely the actual date of drug allergy onset. The advantage of using age on the date of diagnosis provides a more accurate time-point of the confirmed hypersensitivity. However, some patients may have been tested many years later, when they might have developed natural immune tolerance. In this study, there was a high level of correlation ( $r=0.728, P<0.001)$ between patient/parental reporting of the age of onset of drug hypersensitivities and age on date of allergy diagnosis by ST or DPT (Figure 1B). As the onset of drug allergies would be more indicative of the actual age of drug allergies, the onset age was used for multivariate logistic regression, although the age of diagnosis yielded similar significant results.

Table 4. Multivariate logistic regression with odds ratios between patient characteristics and drug hypersensivities.

\begin{tabular}{|lcc|}
\hline & $\begin{array}{c}\text { Odds Ratios and 95\% } \\
\text { CIs for IgE-mediated } \\
\text { Drug Allergy }\end{array}$ & $P$ value \\
\hline $\begin{array}{l}\text { Age of drug hypersensitivities onset } \\
\text { (yrs) }\end{array}$ & $14.9(1.5-148.3)$ & $0.017^{*}$ \\
\hline Male gender & $4.4(1.2-16.4)$ & $0.019^{*}$ \\
\hline & $\begin{array}{l}\text { Odds Ratios and 95\% } \\
\text { CIs for Delayed Drug } \\
\text { Hypersensitivities }\end{array}$ & $P$ value \\
\hline $\begin{array}{l}\text { Age group at drug hypersensitivities } \\
\text { onset (adolescent) }\end{array}$ & $24.0(1.4-417.8)$ & $0.024^{*}$ \\
\hline History of atopic dermatitis & $8.2(1.4-49.8)$ & $0.015^{*}$ \\
\hline
\end{tabular}

Data are odds ratios (and 95\% confidence intervals). ${ }^{*}, P<0.05$. 


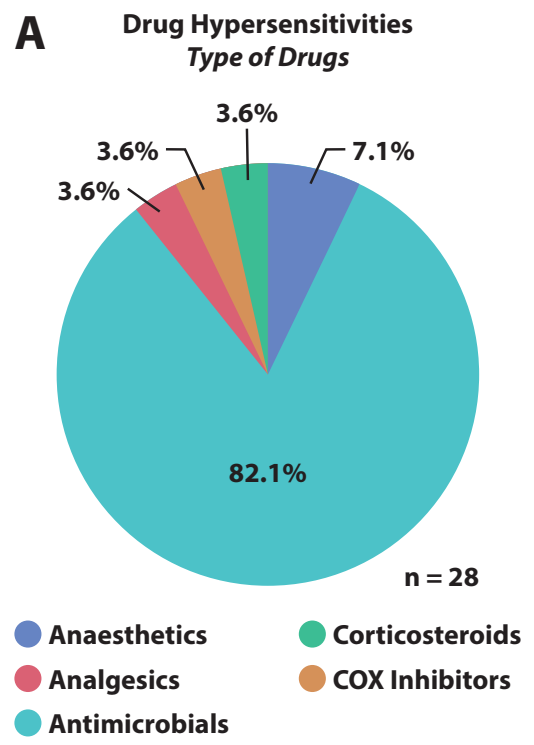

Figure 2. Distributions of (Figure $2 \mathrm{~A}$ ) any drug hypersensitivity $(\boldsymbol{n}$ total $=28)$, with antimicrobials $=23(82.1 \%)$, anaesthetics $=2(7.1 \%)$, analgesics $=1(3.6 \%)$, corticosteroids $=1(3.6 \%)$, cyclooxygenase $(\mathrm{COX})$ inhibitors $=1(3.6 \%)$, and of $($ Figure $2 \mathrm{~B})$ antimicrobials $(n$ total $=23)$, with cephalosporins $=12(52.2 \%)$, penicillins $=9(39.1 \%)$, fluoroquinolones $=1(4.3 \%)$, and lincomycins $=1(4.3 \%)$.

\section{Multivariate logistic regression between age and gender ver- sus drug allergies \\ The age of onset was independently associated with IgE-mediated drug allergies and any drug hypersensitivity $(P$ $<0.05$ ) (Table 4). Additionally, males were more likely to have IgE-mediated drug allergies $(P<0.05)$. Older age groups and a history of atopic dermatitis remained to be significant inde- pendently associated with delayed drug hypersensitivities $(P<$ 0.05).}

\section{Distribution of medications involved in drug allergies}

Of the 26 patients diagnosed with any drug hypersensitivity, $8(30.8 \%)$ were found to have cross reactivity to other similar medications. In contrast, $1(3.8 \%)$ had co-allergies to other unrelated medications. In the total of 28 independent drug allergies, antimicrobials $(n=23,82.1 \%)$ were the most common, followed by anaesthetics $(n=2,7.1 \%$, to lignocaine and tetracaine) (Figure 2A). One had an allergy to paracetamol $(3.8 \%)$, one to mefenamic acid $(3.8 \%)$, and another to hydrocortisone sodium succinate $(3.8 \%)$. Of the antimicrobials, this cohort was most likely allergic to cephalosporins $(n=$ $12,52.2 \%)$ and penicillins $(n=9,39.1 \%)$ (Figure 2B).

\section{Discussion}

In our cohort of 75 Chinese children, older age and male gender were associated with IgE-mediated drug allergies. On the other hand, previous studies examining risk factors for drug allergies had reported mixed results. There is some evidence supporting the notion that Caucasian adult females were more likely to have IgE-mediated drug allergies. ${ }^{16,17}$ The reasons for this observation are unclear but may be related to a differential genetic expression of sex chromosomes, influences of estrogens, or medication use for diseases that are more prevalent in young adult women. ${ }^{26,27}$ Information regarding clinical characteristics that pose risks for children

\section{B Drug Hypersensitivities Type of Antimicrobials}
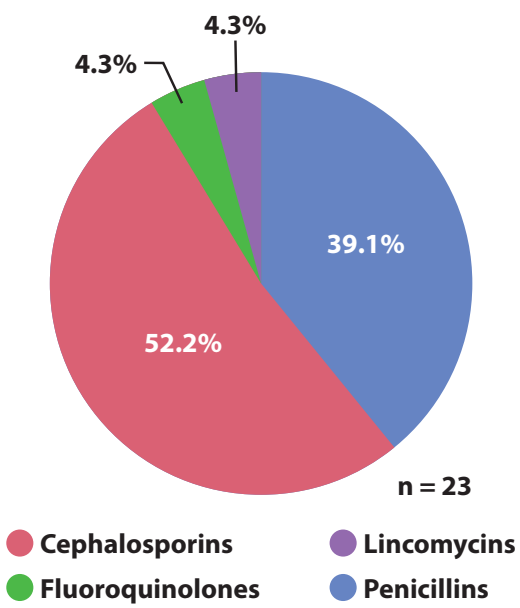

and Asian adults having drug allergies are scarce. Choi and colleagues observed their group of drug allergic children in Korea were older, but this finding was not substantiated in studies that consisted mostly of Middle Eastern and Thai children. ${ }^{18,20}$ Our data are more analogous to the study of Korean children and suggest that East Asian geographical or ethnic factors may contribute to a higher likelihood of development and persistence of drug allergies in adolescent boys. ${ }^{18}$

The exact mechanisms underlying the pathogenesis of drug allergies in humans are still unclear. Based on in vitro experiments and animal models, it is hypothesized that most medications and their metabolites are small molecules that lack the ability to elicit antibody-mediated immunogenic responses and therefore these occur via hapten-carrier conjugate effects or interactions with peptides and T-cell receptors rather than direct IgE binding. ${ }^{28}$ Indeed, patients with certain human leukocyte antigen (HLA) haplotypes, such as HLA-B $^{\star}$ 15:02 predominantly found in Southeast Asians, are at a high risk of potentially life-threatening reactions due to Steven-Johnson syndrome after taking certain medications, including carbamazepine. ${ }^{28}$ Therefore, immunogenetics is a key aspect that underlies the diversity of susceptibilities of patients towards developing drug allergies since specific HLA alleles can be found in higher frequencies in certain ethnic groups, which may explain the differences observed in our Chinese cohort compared to other ethnic groups. ${ }^{28}$ According to our data, teens had higher odds of true immediate drug allergies. It is possible that during this pubertal period, hormonal fluctuations and psychologic stress lead to immunomodulatory changes and these adolescent boys become more prone to drug hypersensitivities. ${ }^{26}$ Additionally, older children are also more likely to have experienced more medication exposure and hence chance of sensitization, although during our chart review, detailed information on past drug use was unavailable. ${ }^{13}$ 
Our retrospective study was limited by the fact that not all data were recorded into our EHR system. Fortunately, the most relevant and essential information was documented by our allergists and retrieved. Despite that, some of these data, for example, the specific onset ages of drug allergies, might have been subjected to recall bias. There was a lack of recorded information on family history as well. The relatively small sample size did not allow sub-categorical analyses on risk factors for allergies to specific types of medications, such as antibiotics, anaesthetics, or anti-inflammatories. ${ }^{29}$ True paediatric drug allergies are uncommon, and recruitment of a large number of subjects for completion of allergy testing by repeated skin prick and intradermal injections in the apprehensive children can be challenging. These are likely reasons that risk factors for paediatric drug allergies are not yet fully studied. In our cohort, $34.7 \%$ was confirmed to have drug allergies, seemingly higher than previous reports which were reported at $10-20 \%{ }^{20}$ The relatively high percentage of confirmed cases of drug allergies in this study was possibly due to selection bias. The scope of our patients consisted of those who were deemed worthwhile by the referring physician for testing at our tertiary allergy center and who were motivated to attend our consultations to complete all steps of allergy testing comprehensively. As a result, these cases may not represent all Chinese children. It is important to note that the ROCs in our sample, although significant based on statistical calculations, did not result in levels of AUC that may translate to the use of 13 years of age as a highly reliable cutoff for predicting drug allergies within the clinical context. As such, these risk factors are more for general predictive rather than diagnostic purposes. Due to the retrospective nature of this study following international guidelines, skin but not blood testing was performed. ${ }^{13,23,24}$ More research, which may include more comprehensive allergy testing (including blood eosinophil count and other allergy testing), basic science laboratory testing of mechanisms, and larger sample size will further enhance our understanding of paediatric drug allergies.

\section{Conclusion}

From these 75 subjects, we were able to identify an overall, consistent association between older age and male gender versus IgE-mediate drug allergies. Therefore, in the clinical setting, a higher level of caution should be considered when performing drug provocation testing in older or male Chinese paediatric patients as they carry a significantly higher risk of genuine drug allergy.

\section{Acknowledgements}

The authors declare no conflicts of interest and thank all the personnel in our department, including Ruth Leung and the rest of the nursing staff, pharmacists, and members of our IT team who support our clinical and research services.

\section{Statement of Contribution}

- Jaime S Rosa Duque was involved in the clinical care, study design, statistical analyses, interpretation of results, and drafting of the manuscript.

- Daniel KL Cheuk was involved in the clinical care, study design, statistical analyses, interpretation of results, and drafting of the manuscript.

- Patrick CY Chong was involved in the clinical care, study design, and drafting of the manuscript.

- Patrick Ip was involved in the clinical care, study design, statistical analyses, interpretation of results, and drafting of the manuscript.

- Wilfred HS Wong was involved in the study design, power analyses, statistical analyses, interpretation of results, and drafting of the manuscript.

- Pamela PW Lee was involved in the clinical care and drafting of the manuscript.

- Ian CK Wong was involved in the interpretation of results and drafting of the manuscript.

- Godfrey CF Chan was involved in the clinical care, interpretation of results, and drafting of the manuscript.

- Yu-Lung Lau was involved in the clinical care, study design, interpretation of results, and drafting of the manuscript.

- Marco HK Ho was involved in the clinical care, study design, statistical analyses, interpretation of results, and drafting of the manuscript.

\section{References}

1. Poudel DR, Acharya P, Ghimire S, Dhital R, Bharati R. Burden of hospitalizations related to adverse drug events in the USA: a retrospective analysis from large inpatient database. Pharmacoepidemiol Drug Saf. 2017;26(6):635-41.

2. Jerschow E, Lin RY, Scaperotti MM, McGinn AP. Fatal anaphylaxis in the United States, 1999-2010: temporal patterns and demographic associations. J Allergy Clin Immunol. 2014;134(6):1318-28.e7.

3. Pumphrey RS. Lessons for management of anaphylaxis from a study of fatal reactions. Clin Exp Allergy. 2000;30(8):1144-50.

4. Liew WK, Williamson E, Tang ML. Anaphylaxis fatalities and admissions in Australia. J Allergy Clin Immunol. 2009;123(2):434-42.

5. Tanno LK, Ganem F, Demoly P, Toscano CM, Bierrenbach AL. Undernotification of anaphylaxis deaths in Brazil due to difficult coding under the ICD-10. Allergy. 2012;67(6):783-9.

6. Mullins RJ, Wainstein BK, Barnes EH, Liew WK, Campbell DE. Increases in anaphylaxis fatalities in Australia from 1997 to 2013. Clin Exp Allergy. 2016;46(8):1099-110.

7. Tanno LK, Bierrenbach AL, Calderon MA, Sheikh A, Simons FE, Demoly P. Decreasing the undernotification of anaphylaxis deaths in Brazil through the International Classification of Diseases (ICD)-11 revision. Allergy. 2017;72(1):120-5.

8. Ko BS, Kim WY, Ryoo SM, Ahn S, Sohn CH, Seo DW, et al. Biphasic reactions in patients with anaphylaxis treated with corticosteroids. Ann Allergy Asthma Immunol. 2015;115(4):312-6.

9. Wang Y, Koplin JJ, Ho MHK, Wong WHS, Allen KJ. Increasing hospital presentations for anaphylaxis in the pediatric population in Hong Kong. J Allergy Clin Immunol Pract. 2018;6(3):1050-2.e2.

10. Pouessel G, Tanno LK, Claverie C, Lejeune S, Labreuche J, Dorkenoo A, et al. Fatal anaphylaxis in children in France: Analysis of national data. Pediatr Allergy Immunol. 2018;29(1):101-4.

11. Brockow K, Aberer W, Atanaskovic-Markovic M, Bavbek S, Bircher A, Bilo B, et al. Drug allergy passport and other documentation for patients with drug hypersensitivity - An ENDA/EAACI Drug Allergy Interest Group Position Paper. Allergy. 2016;71(11):1533-9.

12. Penicillin Allergy in Antibiotic Resistance Workgroup. Penicillin allergy testing should be performed routinely in patients with self-reported penicillin allergy. J Allergy Clin Immunol Pract. 2017;5(2):333-4. 
13. Joint Task Force on Practice Parameters, American Academy of Allergy, Asthma and Immunology, American College of Allergy, Asthma and Immunology, Joint Council of Allergy, Asthma and Immunology. Drug allergy: an updated practice parameter. Ann Allergy Asthma Immunol. 2010;105(4):259-73.

14. Unger NR, Gauthier TP, Cheung LW. Penicillin skin testing: potential implications for antimicrobial stewardship. Pharmacotherapy. 2013;33(8): 856-67.

15. Ho MH, Tung JY, Lee TL, Tsoi NS, Lau YL. Anaphylaxis to paracetamol. J Paediatr Child Health. 2008;44(12):746-7.

16. Mawhirt SL, Fonacier LS, Calixte R, Davis-Lorton M, Aquino MR. Skin testing and drug challenge outcomes in antibiotic-allergic patients with immediate-type hypersensitivity. Ann Allergy Asthma Immunol. 2017;118(1):73-9.

17. Park MA, Matesic D, Markus PJ, Li JT. Female sex as a risk factor for penicillin allergy. Ann Allergy Asthma Immunol. 2007;99(1):54-8.

18. Choi J, Lee JY, Kim KH, Choi J, Ahn K, Kim J. Evaluation of drug provocation tests in Korean children: a single center experience. Asian Pac J Allergy Immunol. 2016;34(2):130-6.

19. Arikoglu T, Aslan G, Batmaz SB, Eskandari G, Helvaci I, Kuyucu S, Diagnostic evaluation and risk factors for drug allergies in children: from clinical history to skin and challenge tests. Int J Clin Pharm. 2015;37(4):583-91.

20. Indradat S, Veskitkul J, Pacharn P, Jirapongsananuruk O, Visitsunthorn N. Provocation proven drug allergy in Thai children with adverse drug reactions. Asian Pac J Allergy Immunol. 2016;34(1):59-64.
21. Campbell DE, Boyle RJ, Thornton CA, Prescott SL. Mechanisms of allergic disease - environmental and genetic determinants for the development of allergy. Clin Exp Allergy. 2015;45(5):844-58.

22. Cheung NT, Fung V, Kong JH. The Hong Kong Hospital Authority's information architecture. Stud Health Technol Inform. 2004;107(Pt 2): 1183-6.

23. Aberer W, Bircher A, Romano A, Blanca M, Campi P, Fernandez J, et al. Drug provocation testing in the diagnosis of drug hypersensitivity reactions: general considerations. Allergy. 2003;58(9):854-63.

24. Brockow K, Garvey LH, Aberer W, Atanaskovic-Markovic M, Barbaud A, Bilo MB, et al. Skin test concentrations for systemically administered drugs -- an ENDA/EAACI Drug Allergy Interest Group position paper. Allergy. 2013;68(6):702-12.

25. Empedrad R, Darter AL, Earl HS, Gruchalla RS. Nonirritating intradermal skin test concentrations for commonly prescribed antibiotics. J Allergy Clin Immunol. 2003;112(3):629-30.

26. Shah S. Hormonal link to autoimmune allergies. ISRN Allergy. 2012;2012:910437.

27. Petri M, Allbritton J. Antibiotic allergy in systemic lupus erythematosus: a case-control study. J Rheumatol. 1992;19(2):265-9.

28. Pirmohamed M, Ostrov DA, Park BK. New genetic findings lead the way to a better understanding of fundamental mechanisms of drug hypersensitivity. J Allergy Clin Immunol. 2015;136(2):236-44.

29. Barni S, Butti D, Mori F, Pucci N, Rossi ME, Cianferoni A, et al Azithromycin is more allergenic than clarithromycin in children with suspected hypersensitivity reaction to macrolides. J Investig Allergol Clin Immunol. 2015;25(2):128-32. 